International Journal of Current Advanced Research

ISSN: O: 2319-6475, ISSN: P: 2319 - 6505, Impact Factor: SJIF: 5.995

Available Online at www.journalijcar.org

Volume 6; Issue 5; May 2017; Page No. 3656-3659

DOI: http://dx.doi.org/10.24327/ijcar.2017.3659.0340

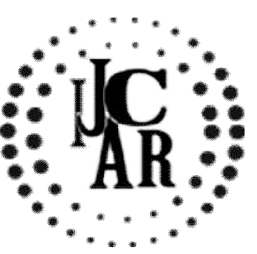

Research Article

\title{
PREVALENCE AND RISK FACTORS ASSOCIATED WITH HYPERTENSION AMONG CHILDREN AND ADOLESCENTS
}

*Kiren J and Jothi Priya

Department of Physiology Saveetha Dental College and Hospitals, 162, Poonamallee high road, Velappanchavadi Chennai-600077, Tamil Nadu, India

\section{A R T I C L E \\ Article History: \\ Received $24^{\text {th }}$ February, 2017 \\ Received in revised form $12^{\text {th }}$ March, 2017 \\ Accepted $15^{\text {th }}$ April, 2017 \\ Published online $28^{\text {th }}$ May, 2017}

\section{Key words:}

Adolescents, children, hypertension, prevalence, risk factors

\begin{abstract}
A B S T R A C T
Background: Primary hypertension is detectable in children and adolescents as in adults. It is associated with a positive family history of hypertension, obesity, and life-style factors. Hypertension has been increasing among children and adolescents since1990s.

Objective: The objective of the study is to determine the prevalence of childhood and adolescent hypertension and its risk factors.

Materials and methods: This is an observational study carried out among children and adolescents at a selected private clinic in Chennai, India. Convenient sampling technique was used to select the participants. The questionnaire consists of demographic profile, questionnaire related to risk factors and blood pressure readings.

Results: The results of this study show that the mean systolic BP for boys and girls are normal between all the age groups. The mean diastolic pressure for both boys and girls are also found to be normal. Though the mean blood pressure readings of boys and girls for both systolic and diastolic are found to be normal among the ages between 5-19 years, there are still few risk factors found to be present in the history.

Conclusion: There are more than half of them 25 (55.6\%) who had family history of hypertension (both maternal and paternal). Children with family history of hypertension should therefore, be targeted for primary prevention in vigorous manner along with dietary and lifestyle modification.
\end{abstract}

Copyright $\bigcirc 2017$ Kiren J and Jothi Priya. This is an open access article distributed under the Creative Commons Attribution License, which permits unrestricted use, distribution, and reproduction in any medium, provided the original work is properly cited.

\section{INTRODUCTION}

Hypertension has been identified as the leading risk factor for mortality, and is ranked third as a cause of disability-adjusted life-years [1]. According to WHO (2002), the number of people worldwide afflicted with hypertension was about 600 million[2].The hospitalization rate for children and adolescents with a diagnosis of hypertension during 19972006, doubled from approximately 18 cases per 100,000 paediatric hospital discharges in 1997 to approximately 35 cases per 100,000 in 2006. Among children and adolescents with hypertension, as many as one in three has target organ damage, especially left ventricular hypertrophy [3]. Various factors might have attributed to this rising trend like changing life style, diet and urbanization. Blood pressure normally changes with growth and development. So, it becomes increasingly important to detect and interrupt development of

\section{*Corresponding author: Kiren J}

Department of Physiology Saveetha Dental College and Hospitals, 162, Poonamallee high road,

Velappanchavadi Chennai-600077, Tamil Nadu, India childhood and adolescent hypertension to reduce long term ill effect of the disease [4]. Owing to the well-established childhood obesity epidemic, the population prevalence of high blood pressure (BP) in the young is increasing. Hypertension in childhood is commonly associated with other cardiovascular risk factors as well as obesity. Although death and cardiovascular disability do not occur in hypertensive children, intermediate markers of target organ damage, such as left ventricular hypertrophy, thickening of the carotid vessel wall, retinal vascular changes, and even subtle cognitive changes, are detectable in children and adolescents with high blood pressure [5]. Thus this study aims to determine the prevalence of hypertension and risk factors among children and adolescents.

A study conducted by in Italy by Menghetti et al, (2015) shows that the prevalence of hypertension has increased in the past years and hypertensive children are more prevalent in north Italy. An excess use of salt could explain the greater rate of hypertension among children living in the north Italy [6]. The findings of the study conducted in Bangladesh on 'Hypertension and associated risk factors in some selected 
rural areas' shows that the prevalence of systolic hypertension among the respondents is $15.6 \%$ and that of diastolic pressure are $12.3 \%$. Systolic pressure was found in an increasing manner with the increase of age and BMI. Tendency of increase systolic pressure was observed among those who took extra salt [7]. A study conducted in Kerala, India (2009) shows that the overall prevalence of hypertension was $47 \%$. Among all the participants, $21.6 \%$ had stage-I hypertension, $9.34 \%$ had stage-II hypertension. Only $11.4 \%$ individuals had normal BP, while $41.7 \%$ were prehypertensives. Only $16.8 \%$ hypertensive patients were aware of their disease. High salt diet had a significant association with hypertensive state [8].

\section{MATERIALS AND METHODS}

This is a descriptive observational study carried out among children and adolescents in a selected clinic at Chennai, India. food items in their diet. Junk food includes food items like potato chips, samosa, cold drinks, etc. Descriptive statistics was used for data analysis. The results were analysed and presented in tables and figures. The study was approved by the Institutional Review Board. Informed consent was obtained from the parents and participants before the data collection.

\section{RESULTS}

The demographic data results are shown in Figure 1 and 2.There were $25(55.6 \%)$ participants who belonged to the age group of $15-19$ years, 11 (24.4\%) of them between 5-10 years and $9(20 \%)$ belonged to the age group between $10-15$ years. There were $30(66.7 \%)$ female participants and $15(33.3 \%)$

Table 1 Distribution of mean systolic BP for boys and girls at different age group

\begin{tabular}{llllllr}
\hline Age group & Males (n) & $\begin{array}{c}\text { Male Mean SBP } \\
(\mathbf{m m ~ H g})\end{array}$ & SD & Females (n) & $\begin{array}{c}\text { Female Mean SBP SD } \\
(\mathbf{m m} \mathbf{H g})\end{array}$ \\
\hline & & & & & \\
5-10 Years & 5 & 107.6 & 8.87 & 6 & 110 & 5.38 \\
10-15 Years & 3 & 108.3 & 7.63 & 6 & 113.5 & 3.78 \\
$15-19$ Years & 7 & 117.8 & 8.07 & 18 & 108.7 & 12.04 \\
Total & 15 & & 30 & & \\
\hline
\end{tabular}

Table 2 Distribution of mean diastolic BP for boys and girls at different age group

\begin{tabular}{lllllll}
\hline Age group & Males (n) & $\begin{array}{l}\text { Male Mean SBP } \\
(\mathbf{m m} \text { Hg) }\end{array}$ & SD & Females (n) & $\begin{array}{l}\text { Female Mean SBP } \\
(\mathbf{m m} \text { Hg) }\end{array}$ & SD \\
\hline 5-10 Years & 5 & 64.4 & 5.17 & 6 & & 68 \\
10-15 Years & 3 & 70 & 10 & 6 & 72 & 6.57 \\
15-19 Years & 7 & 78.4 & 7.27 & 18 & 73 & 8.28 \\
Total & 15 & & & 30 & & \\
\hline
\end{tabular}

Table 3 Risk Factors of hypertension among children and adolescents $(n=45)$

\begin{tabular}{lcc}
\hline Risk Factors & Yes (\%) & No (\%) \\
\hline $\begin{array}{l}\text { Family history of Hypertension } \\
\text { (both paternal and maternal) }\end{array}$ & $25(55.6 \%)$ & $20(44.4 \%)$ \\
Maternal history of hypertension & & \\
Paternal history of hypertension & $11(24.4 \%)$ & $39(86.7 \%)$ \\
$\begin{array}{l}\text { Type of diet } \\
\text { a. Vegetarian }\end{array}$ & $12(26.7 \%)$ & $34(75.6 \%)$ \\
b. Non- vegetarian & $33(73.3 \%)$ & --- \\
Additional salt intake & $23(51.1 \%)$ & -- \\
Intake of junk food & $12(26.7 \%)$ & $22(48.9 \%)$ \\
a. Daily & $12(26.7 \%)$ & --- \\
b. Weekly & $14(31.1 \%)$ & --- \\
c. Monthly & $7(15.6 \%)$ & --- \\
d. None & & \\
\hline
\end{tabular}

All children and adolescents aged 5 to 19 years along with their parents who attended the clinic were included in the study. The total number of samples who participated in this study was 45. Convenient sampling technique was used to select the participants. Blood pressure (BP) was measured in the seated position using a digital sphygmomanometer. Data was collected using a questionnaire completed by parents for children below 10 years. The questionnaire consists of Part A: demographic profile (Age and gender), Part B: questionnaire related to risk factors and blood pressure readings.According to dietary history, subjects were categorized vegetarians if they never consumed non-vegetarian food at any time in their life and non-vegetarians if they consumed non-vegetarian male participants in this study. Table 1 shows the results of the mean systolic BP for boys and girls at different age group. Male systolic mean BP was found to be between 107.6 to $117.8 \mathrm{mmHg}$ and the male diastolic mean BP was found to be between 64.4 and $78.4 \mathrm{~mm} \mathrm{Hg}$ among all the age groups. These values of both systolic and diastolic mean BP for boys are normal according to the PALS (Paediatric Advanced Life Support) guidelines, 2015 [9].

Table 2 shows the mean diastolic BP for boys and girls at different age group. The female systolic BP was found to be 108.7 to $113.5 \mathrm{~mm} \mathrm{Hg}$ and the female diastolic mean BP was found to be between 68 and $73 \mathrm{~mm} \mathrm{Hg}$ among all the age 
groups. These values of both systolic and diastolic mean BP for girls are normal (PALS guidelines, 2015).

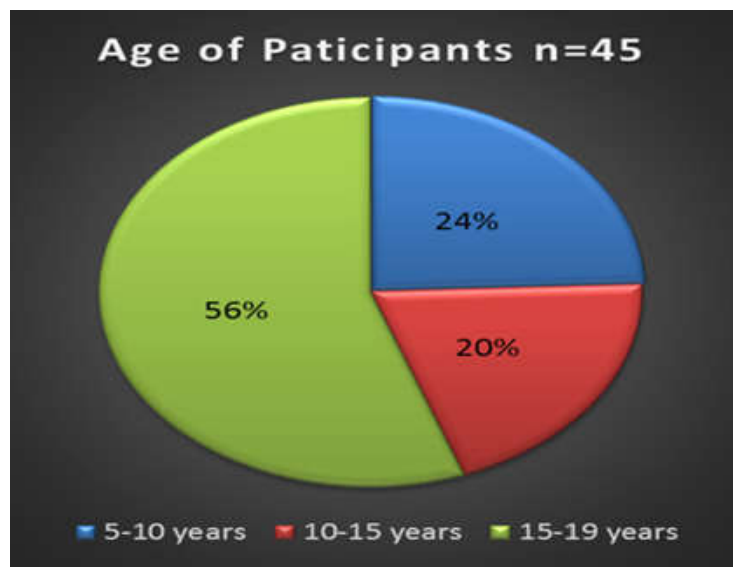

Figure 1 Age of participants $(n=45)$

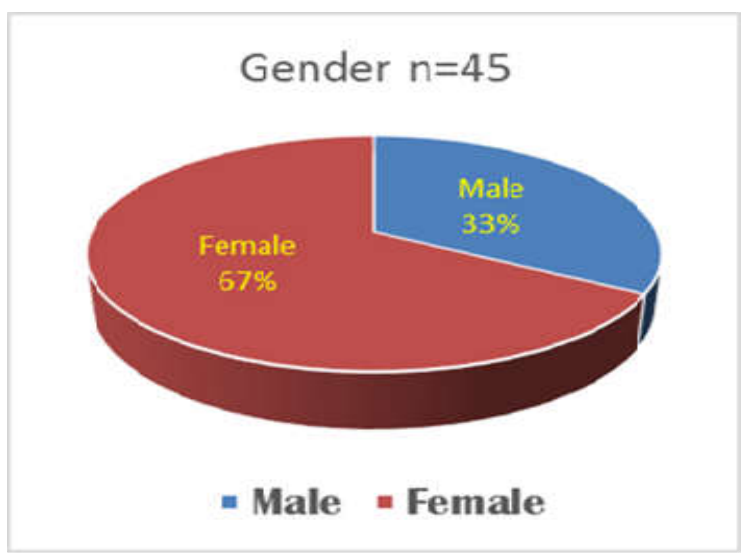

Figure 2 Gender of participants $(n=45)$

Table 3 shows the results for the questionnaire on the risk factors of hypertension among children and adolescents. More than half of them $25(55.6 \%)$ had family history of hypertension (both maternal and paternal) and 20(44.4\%) did not have any family history of hypertension. Only $6(13.3 \%)$ had history of maternal history and $11(24.4 \%)$ had paternal history of hypertension. Among the 45 participants, $12(26.7 \%)$ were vegetarians and $33(73.3 \%)$ were nonvegetarians. About half of the participants 23(51.1\%) take additional salt intake in their diet and 22(48.9\%) of them do not consume additional salt. With regards to the intake of junk food, $12(26.7 \%)$ of them take junk food daily and weekly, 14 $(31.1 \%)$ of them take monthly and only $7(15.6 \%)$ of them do not take junk food at all.

\section{DISCUSSION}

The results of this study show that the mean systolic BP for boys and girls are normal between all the age groups. The mean diastolic pressure for both boys and girls are also found to be normal. The values are found to be normal according to the PALS Guidelines (2015). About 33(73.3\%) were nonvegetarians and half of the participants $23(51.1 \%)$ take additional salt intake in their diet, which is a high risk factor for developing hypertension in the future. There is a gradual increase of BP over age in this study, which is similar to the study conducted in Bihar, India by Kumar A et al (2015).
A study conducted in Uttar Pradesh by Agarwal et al, India shows that there is a significant association found between hypertension and additional salt intake [10]. The other risk factor is the intake of junk food, in which 12(26.7\%) of them take junk food daily and weekly. There are more than half of them $25(55.6 \%)$ who had family history of hypertension (both maternal and paternal). The study finding is similar to the study done by Mijinyawa et al in Nigeria shows that the prevalence rate of hypertension raised from $4.3 \%$ (among the younger participants) to $11.8 \%$ among the oldest students. Of the 70 , a majority $(88.5 \%$ ) had grade 1 hypertension, $10.0 \%$ had Grade 2 hypertension and $1.5 \%$ had Grade 3 hypertension. The hypertensives were about twice more likely to have a family history of hypertension compared to their normotensive counterparts. Adolescent hypertensives in Kano, Nigeria were twice more likely to have family history of hypertension than their normotensive counterparts [11]. A study conducted in Karnataka, India among the first year medical students showed that young normotensives with a positive family history of hypertension had significantly higher blood pressure $(p<0.005)$ and also increased resting heart rate $(\mathrm{p}<0.05)$ than young normotensives with a negative family history of hypertension[12]. Though, in this study, the mean blood pressure readings of boys and girls for both systolic and diastolic are found to be normal among the ages between 5-19 years, there are still few risk factors found to be present in the history.

\section{CONCLUSION}

Children with family history of hypertension should therefore, be targeted for primary prevention in vigorous manner along with dietary and lifestyle modification. Knowledge about prevalence, early and appropriate diagnosis is important since even a small change in blood pressure can have substantial effect on cardiovascular health (Kumar A et al, 2015). Routine blood pressure measurements should be taken in school children to improve the detection, prevention and treatment of hypertension. Although the study results shows that the children and adolescents have normal systolic and diastolic blood pressure readings, significant interventions to promote awareness in the prevention of the hypertension and associated risk factors is essential.

\section{Acknowledgement}

The authors wish to thank Saveetha Dental College and hospital for the approval and permission to conduct the study. The authors appreciate the head of the department for the continuous support. The subjects are highly appreciated for their participation in this study.

\section{References}

1. Ezzati, M., Lopez, A.D., Rodgers, A., Vander Hoorn, S., Murray, C.J., Selected major risk factors and global and regional burden of disease. Lancet. 2002, 360, 1347-60.

2. World Health Organization: Global Health Observatory (GHO). Raised blood pressure: situation and trend, 2002. Availableat:

http://www.who.int/gho/ncd/risk_factors/blood_pres sure_prevalence_text/en/. 
3. Kumar, A et al., Prevalence and risk factors associated with hypertension in children and adolescents. Pediatriconcall journal. 2015, 12.

4. Leupker, R.V., ,Jacobe, D.R., Prineas, R.J., Sinaiko, A.R., Secular trends of blood pressure and body size in a multi-ethinic adolescent population.1986-96; $J$ Paediatr.1999, 134, 668-78.

5. Bonita, F., Hypertension in children and adolescents: epidemiology and natural history. PediatrNephrol. 2010, 25, 1219-1224.

6. Menghetti, E et al., Hypertension and obesity in Italian school children: The role of diet, lifestyle and family history; Nutrition, Metabolism and Cardiovascular diseases. Nutrition, Metabolism \& Cardiovascular Diseases. 2015, 25, 602-607.

7. Ahmed, A et al., Hypertension and associated risk factors in some selected rural areas of Bangladesh. Int $J$ Res Med Sci. 2014, 2, 925-931.

8. Vimala, A., Ranji, S.A., Jyosna, M.T., Chandran, V., Mathews, S.R., Pappachan, J.M., The prevalence, risk factors and awareness of hypertension in an urban population of Kerala (South India). Saudi J Kidney Dis Transpl. 2009, 20, 685-689.

\section{How to cite this article:}

Kiren J and Jothi Priya (2017) ' Prevalence And Risk Factors Associated With Hypertension Among Children And Adolescents', International Journal of Current Advanced Research, 06(05), pp. 3656-3659.

DOI: http://dx.doi.org/10.24327/ijcar.2017.3659.0340

9. Pediatric vital signs reference chart. Retrieved on 30th December 2016 from www.pedscases.com/pediatricvital-signs-reference-chart.

10. Agarwal, A.K., Yunus, M., Khan, A., Ahmad, J., A clinical-epidemiological study of hypertension in rural population of jawan block, Distt Aligarh (UP), India. $J$ $R$ Soc Health. 1994, 114, 17-9.

11. Mijinyawa, M.S., Iliyasu, Z., Borodo, M.M., Prevalence of hypertension among teenage students in Kano, Nigeria. Niger J Med. 2008, 17, 173-178.

12. Dayananda, G., Murthy, N., Blood pressure changes in normotensive subjects with and without family history of hypertension. $J$ Physiological and Biomedical Sciences. 2009, 22, 35-37. 